\title{
FRACTURE STRENGTH OF FLARED BOVINE ROOTS RESTORED WITH DIFFERENT INTRARADICULAR POSTS
}

\author{
Victor Grover Rene CLAVIJO ${ }^{1}$, José Maurício dos Santos Nunes REIS², William KABBACH¹, André Luis Faria e SILVA, \\ Osmir Batista de OLIVEIRA JUNIOR ${ }^{4}$, Marcelo Ferrarezi de ANDRADE ${ }^{4}$
}

\author{
1- DDS, MSc PhD student, Department of Restorative Dentistry, Araraquara Dental School, São Paulo State University, Araraquara, SP, Brazil. \\ 2- DDS, MSc, PhD, Substitute Professor, Department of Dental Materials and Prosthodontics, Araraquara Dental School, São Paulo State University, \\ Araraquara, SP, Brazil. \\ 3- DDS, MSc, PhD student, Department of Restorative Dentistry, Piracicaba Dental School, State University of Campinas, Piracicaba, SP, Brazil. \\ 4- DDS, MSc, PhD, Associate Professor, Department of Restorative Dentistry, Araraquara Dental School, São Paulo State University, Araraquara, SP, \\ Brazil.
}

Corresponding address: Prof. José Maurício dos Santos Nunes Reis - Faculdade de Odontologia de Araraquara - UNESP - Departamento de Materiais Odontológicos e Prótese -Rua Humaitá, nº 1680 - 14801-903 - Araraquara, SP - Brasil - Phone: +55 016 3301-6408 - Fax: +55 016 $3301-6406$ - e-mail: reisunesp@hotmail.com / josemsnreis@foar.unesp.br

Received: August 19, 2008 - Modification: May 18, 2009 - Accepted: July 21, 2009

\begin{abstract}
$O$

bjective: The aim of this study was to evaluate the fracture strength and failure mode of flared bovine roots restored with different intraradicular posts. Material and Methods: Fifty bovine incisors with similar dimensions were selected and their roots were flared until $1.0 \mathrm{~mm}$ of dentin wall remained. Next, the roots were allocated into five groups $(\mathrm{n}=10)$ : GI- cast metal post-andcore; GII- fiber posts plus accessory fiber posts; GIII- direct anatomic post; GIV- indirect anatomic post and GV- control (specimens without intraradicular post). A polyether impression material was used to simulate the periodontal ligament. After periodontal ligament simulation, the specimens were subjected to a compressive load at a crosshead speed of $0.5 \mathrm{~mm} / \mathrm{min}$ in a servo-hydraulic testing machine (MTS 810) applied at $135^{\circ}$ to the long axis of the tooth until failure. The data (N) were subjected to ANOVA and Tukey's post-hoc test $(\alpha=0.05)$. Results: GI and GIV presented higher fracture strength $(p<0.05)$ than GII. GIII presented intermediate values without statistically significant differences ( $p>0.05$ ) from GI, GII and GIV. Control specimens (GV) produced the lowest fracture strength mean values $(p<0.05)$. Despite obtaining the highest mean value, GI presented $100 \%$ of unfavorable failures. GII presented $20 \%$ of unfavorable failures. GIII, GIV and GV presented only favorable failures. Conclusions: Although further in vitro and in vivo studies are necessary, the results of this study showed that the use of direct and indirect anatomic posts in flared roots could be an alternative to cast metal post-and-core.
\end{abstract}

Key words: Post and core technique. Compressive strength. Prosthodontics.

\section{INTRODUCTION}

Intraradicular posts are commonly used to restore endodontically treated teeth when their remaining coronal tissue can no longer provide adequate support and retention for the restoration material. However, flared canal restoration continues to be a challenge to clinicians. The flared canal may result from carious extension, trauma, pulpal pathosis and iatrogenic misadventure ${ }^{20}$.

Endodontically treated teeth have been restored using cast metal post-and-core for decades. Instead the high retention and thin cement layer, these conventional posts present high elastic modulus and can lead to root fracture ${ }^{13,16,19,24,26}$. Another option is to use fiber posts ${ }^{1,16,26}$. The similarity in elastic modulus of the fiber post, resin cement and dentin was perceived to be advantageous for

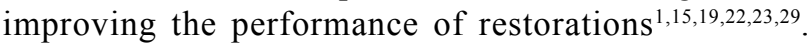

However, the use of fiber posts in flared root canals is compromised. In this case, if the post does not fit well, especially at the coronal level, the resin cement layer would be excessively thick, and bubbles are likely to form within it, predisposing to debonding ${ }^{14}$.

One solution to overcome this problem is the use of dentin-bonded composite resin. This technique increases the internal thickness of dentin on root walls and reduces the resin cement thickness ${ }^{5,15}$. However, light-activation of composite resin in more apical regions of the root canal is difficult and may compromise this technique. Another solution is to reline the fiber post with composite resin. This individual post system increases the adaptation of the post to root walls and reduces the resin cement thickness ${ }^{5,15}$. However, this technique presents another interface (fiber post-composite resin) that may lead to failure. Thus, fabricating an individual fiber post-resin composite may 
overcome this disadvantage. Therefore, the aim of this study was to evaluate the fracture strength and failure mode of flared bovine roots restored with different posts fabricated by different techniques. The null hypothesis tested is that the post manufacturing technique has no influence on the fracture strength and failure mode of flared roots.

\section{MATERIAL AND METHODS}

Fifty recently extracted bovine incisors with similar dimensions were selected for this study. The teeth were examined under a $\times 4$ magnifying glass to discard those with carious lesions, cracks or fractures. Buccolingual and mesiodistal radiographs were taken to demonstrate that the teeth had similar internal anatomy ${ }^{4}$. The crowns were removed above the cementoenamel junction (CEJ) with a water-cooled low-speed diamond saw in order to obtain a remaining root height of $14 \mathrm{~mm}$. For the endodontic treatment, a step-back preparation technique was used with stainless-steel K-files (Dentsply/Maillefer Instruments SA) and Gates-Glidden drills sizes 2-4 (Dentsply/Maillefer Instruments SA, Ballaigues, Switzerland). All enlargement procedures were followed by irrigation with $1.0 \%$ sodium hypochlorite $(\mathrm{NaOCl})$. After instrumentation, root canals were cleaned with $15 \%$ EDTA and filled with gutta-percha cones (Dentsply Indústria e Comércio Ltda., Petropolis, RJ, Brazil) and Sealer 26 resin cement (Dentsply Indústria e Comércio Ltda., Petropolis, RJ, Brazil) using the lateral condensation technique. After endodontic treatment, the roots were sealed with conventional glass ionomer cement (Ketac-Bond, 3M/ESPE, Sumaré, SP, Brazil) and stored in a stove at $37^{\circ} \mathrm{C}$ and $100 \%$ relative humidity for $48 \mathrm{~h}^{4}$.

After storage, the coronal gutta-percha was removed with a heated Rhein instrument and 4.0-mm-thick gutta-percha layer was left for apical sealing. In order to obtain a simulated flared canal, the root canals were enlarged with high-speed diamond burs (sizes 1018 and 4138; KG Sorensen, Industria e Comercio Ltda, Sao Paulo, SP, Brazil) followed by a lowspeed bur ( DB 14; Renfert, Hilzingen, Germany). The depth of the post space preparation was $10 \mathrm{~mm}$ and the remaining dentin wall was approximately $1.0 \mathrm{~mm}$ thick, measured with a digital caliper accurate to the nearest $0.01 \mathrm{~mm}$. To standardize the thickness of the dentin walls, reference points were located around the cervical portion of the root (Figure 1) using a periodontal probe (Hu-fried, Chicago, IL, USA). During the procedures, the roots were maintained involved in moist gauze and were irrigated with $1.0 \% \mathrm{NaOCl}$. After flaring, buccolingual and mesiodistal radiographs were taken to ensure that the roots had similar dentin wall thickness.

To reproduce the clinical situation and to provide a more accurate assessment of bovine root fracture strength, the methodology of the present study included tooth embedding in polystyrene resin (Cristal, Piracicaba, SP, Brazil) and periodontal ligament simulation using a polyether impression material (Impregum TM Soft, 3M/ESPE AG, Seefeld, Germany). The periodontal ligament was simulated using the method described by Soares, et al. ${ }^{27}$ (2005). Initially,

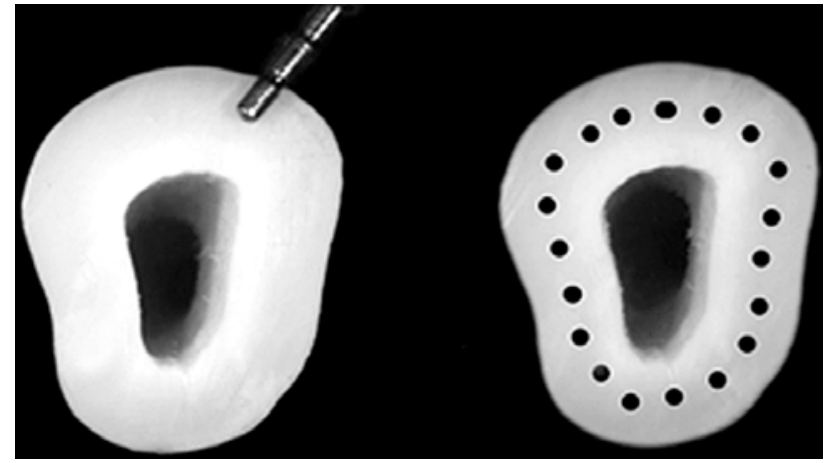

FIGURE 1- Reference points located around the cervical portion of the root

root surfaces were dipped into melted wax (Horus; Herpo Produtos Dentários, Petrópolis, RJ, Brazil) up to $3.0 \mathrm{~mm}$ below the CEJ, resulting in a 0.2 to $0.3 \mathrm{~mm}$ thick wax layer. Then, the teeth were embedded in polystyrene resin using polyvinyl chloride (PVC) cylinders (21 mm diameter x 25 $\mathrm{mm}$ high) as molds. The resin was mixed according to the manufacturer's instructions and was inserted in the PVC cylinder immediately after mixing. After resin polymerization, the teeth were removed from the PVC cylinders, and the wax was removed from root surface and resin cylinder 'sockets' using warm water ${ }^{27}$. The resin cylinders were filled with the polyether impression material using a molding syringe. The teeth were re-inserted into their respective cylinder 'sockets' and excess impression material was removed with a \#12 scalpel blade. Therefore, the polyether filled the space previously occupied by wax, thus providing a standardized simulated periodontal ligament with a thickness of 0.2 to $0.3 \mathrm{~mm}^{27}$. The flared roots were randomly assigned to 5 experimental groups $(n=10)$.

\section{GI - Cast metal post-and-core}

A cast metal post-and-core was obtained by direct modeling with acrylic resin (Duralay; Reliance Dental Manufacturing Company, Chicago, IL, USA). The final resin pattern had an intraradicular portion with passive taper, coronal portion with a standardized height of $5.0 \mathrm{~mm}$ and a step at the palatal surface used as a standardized point for load application ${ }^{21}$. These resin patterns were cast with Ni$\mathrm{Cr}$ alloy. Impressions of the coronal portion were made with a polyvinylsiloxane impression material (Elite; Zhermack, Badio Polinese, Rovigo, Italy) in order to standardize all cast post-and-cores. The posts were cemented with dualcured resin cement (Multilink; Ivoclar-Vivadent, Liechtenstein, Germany).

\section{GII - Fiber post plus accessory posts}

A 1.5-mm-diameter glass fiber-reinforced composite post system (Reforpost; Angelus, Londrina, PR, Brazil) was used as the main post. The remaining empty spaces were filled with accessory fiber posts (Reforpin; Angelus). Both fiber posts were cleaned with ethanol and treated with an application of silane coupling agent before cementation. After the fiber post cementation with Multilink, the core 
was built-up with composite resin (Tetric Ceram; IvoclarVivadent). During core construction, a matrix with the same dimensions as the core of the previous group was used.

\section{GIII - Direct anatomic post (fiber post relined with composite resin)}

The direct anatomic post was fabricated using the method described by Grandini, et al. ${ }^{15}$ (2003). After lubricating the canal walls with glycerin gel, the fiber post Reforpost was covered with Tetric Ceram composite resin and inserted into the canal. The composite resin was photoactivated for $10 \mathrm{~s}$ and the post-resin composite was removed from canal and fully photoactivated for other $60 \mathrm{~s}$. Copious rinsing was performed to remove the lubricant gel and the post was cemented with Multilink resin cement. The core was builtup as described for Group GII.

\section{GIV - Indirect anatomic post}

For this group, the Fibrex-lab system (Angelus) was used. Initially, impressions of the root canal were made with Duralay acrylic resin. The impressions were lubricated and covered with hot glue following the manufacturer's instructions. After the glue cooled, the impressions were removed and replicas of the root canal were obtained. Medium unidirectional glass fibers (Fibrex-lab) with the respective flowable resin were inserted into to the replica. The flowable resin was photoactivated for $5 \mathrm{~min}$ according to the manufacturer's instructions. The post was removed from the replica and cemented in the root canal with Multilink resin cement. The core was built-up as described for GII and GIII.

\section{GV - Control group}

In order to analyze the influence of the different intraradicular posts on the fracture strength of the flared roots, control specimens without posts were obtained. In these teeth, the intraradicular portion of the flared roots was only filled with gutta-percha cones and Sealer 26 resin cement. After that, $2.0 \mathrm{~mm}$ of coronal gutta-percha were removed and cores with the same dimensions of those from the experimental groups were constructed using composite resin, however, without using intraradicular posts.

\section{Fracture strength testing}

All specimens were subjected to a compressive load at a crosshead speed of $0.5 \mathrm{~mm} / \mathrm{min}^{4,27}$ in a servo-hydraulic testing machine (MTS 810; MTS Systems Corporation, Eden Prairie, MN, USA) until fracture. The load was applied on the palatal aspect of specimens at $135^{\circ}$ to the long axis of the teeth (Figure 2) ) $^{4,21}$. After testing, the failure mode was classified under microscope analysis ${ }^{11}$. Root fractures at the cervical third were classified as favorable, while fractures at the middle and apical thirds were classified as unfavorable. The fracture strength data $(\mathrm{N})$ were subjected to one-way ANOVA followed by Tukey's post-hoc test at 95\% level of confidence.



FIGURE 2- Cylindrical device used for fixation and positioning of the specimens subjected to fracture strength testing. Device positioned for load application at $135^{\circ}$

\section{RESULTS}

Table 1 shows fracture strength data $(\mathrm{N})$ for each experimental group. The post type had a statistically significant effect $(p<0.05)$ on the fracture strength of the flared root canals. GI (cast metal post-and-core) and GIV (indirect anatomic post) presented similar values ( $p>0.05)$, which were significantly higher $(\mathrm{p}<0.05)$ than those of GII (fiber post plus accessory posts) and GV (control specimens). GIII (direct anatomic post) produced intermediate fracture strength values without statistically significant differences ( $p>0.05)$ from GI, GII and GIV. All GI's fractures were classified as unfavorable, while GIII, GIV and GV presented $100 \%$ of favorable fractures. For GII, $80 \%$ of the fractures were classified as favorable.

TABLE 1- Means of fracture strength $(\mathrm{N})$

\begin{tabular}{ll}
\hline Group & Mean \\
\hline GI & $575.54 \mathrm{~A}$ \\
GII & $400.49 \mathrm{~B}$ \\
GIII & $483.39 \mathrm{AB}$ \\
GIV & $559.19 \mathrm{~A}$ \\
GV & $249.38 \mathrm{C}$ \\
\hline
\end{tabular}

Different letters indicate statistically significant difference (Tukey's post-hoc test; $\mathrm{p}<0.05$ ). 


\section{DISCUSSION}

Regarding the restoration of a severely damaged tooth, such as an endodontically treated tooth with thin root walls and flared canal, clinicians are continuously faced with a dilemma of whether to extract it or not. Due to loss of a large amount of radicular structure, a flared canal is structurally weak and poses a higher risk of biomechanical failure when compared to a tooth with ample radicular dentin structure. Weakened roots are often encountered in clinical practice and require a post system in order to continue being used as support for a crown or fixed partial denture ${ }^{1,26,30}$. This study investigated the fracture strength of simulated flared bovine roots after restoration using different post systems. The technique used for post fabrication was shown to have significant effect on the fracture strength and failure mode of the bovine roots. Thus, the null hypothesis was rejected.

In the past, the cast metal post-and-core was widely accepted for every pulpless tooth irrespective of the amount of remaining supportive tooth structure ${ }^{18,25}$. In the present study, this type of post presented high fracture strength values. The mechanical properties of cast metal, in particular the modulus of elasticity, are far higher than those of dentin and fiber post ${ }^{26}$. This high modulus of elasticity is responsible for less bending of the post and core under load, resulting in high strength ${ }^{11}$. In addition, the juxtaposition between the posts and the root canals minimizes the cement layer and may contribute to an increase on the fracture strength of the weakened roots ${ }^{30}$. On the other hand, despite the higher load required to fracture, the metal concentrates stress, mainly at the apical root third. Thus, after some time, the highly concentrated stress is transmitted to the dentin walls and may result in root fracture ${ }^{28}$. Therefore, this phenomenon may explain the unfavorable mode of fracture when cast metal post-and-core was used. Similar outcomes were found by several authors ${ }^{3,16}$.

Fiber posts have a low modulus of elasticity and the stress generated by the load is distributed evenly along the length of the post $\mathrm{t}^{7,10,12,17}$. Duret, et al. ${ }^{8}(1990)$ reported that this type of post transmits stress between the post and the remaining root structure, reducing stress concentration. Another factor that increases the stress distribution is the possibility of bonding between the fiber post and dentin $\operatorname{root}^{9,10,14}$. The fiber post is covered by epoxy resin that can chemically bond to the resin cement through the silane agent. It is believed that the possibility of monoblock creation helps transmitting stress applied over the tooth ${ }^{2,5,16}$. Thus, the possibility of unfavorable root fracture may be reduced. The fracture modes found in the present study were more favorable for fiber post systems than cast metal post-andcore system. This is in according to several in vivo and in vitro studies ${ }^{3,7,9,10,12,17,23}$. However, there was difference between the post manufacturing techniques when the fiber posts were used.

The group that used accessory posts (GII) showed the lowest values among the post-restored specimens and differed significantly from GIV (indirect anatomic post). A possible explanation may be the use of a thick layer of resin cement. It may be assumed that in this technique, insertion of the accessory fiber post, which presents a small diameter, created a large number of empty spaces that were filled by resin cement. Thus, the thicker cement layer was more inclined to present large lacunae or bubbles, reducing the cohesive strength of the resin cement ${ }^{14}$. In addition, the application of a large volume of cement in the root canal induced high stress at the adhesive interfaces, due to the high polymerization shrinkage, and could lead to debonding ${ }^{6}$. Therefore, the adhesive failures may have reduced the stress distribution along the root canal and may have played an important role on the fracture strength and failure mode of the flared roots.

In order to reduce the resin cement layer thickness and it disadvantages, Boudrias, et al. ${ }^{5}$ (2001) described the use of anatomic post. In this technique, the fiber post is relined into the root canal replacing the resin cement by the composite resin, which has better mechanical and physical properties. The enhanced mechanical properties lead to the direct anatomic post presenting fracture strength values similar to those of the cast metal post-and-core. However, in the present study, no significant difference was found between the direct anatomic post and the accessory posts. The technique for fabrication of direct anatomic posts is relatively easy. In addition, by adding only a few more steps to those required to lute a conventional fiber post, it is possible to achieve better fitting quality. Moreover, the thickness of the cement layer, in which voids and bubbles are likely to develop, can be minimized ${ }^{14,15}$.

When the anatomic post was fabricated by the indirect method, fracture strength was enhanced and the values were higher than those reached with the use of accessory fibers. This increased fracture strength may be related to the fact of the indirect anatomic post having a lower amount of resin cement than the fiber post and accessory posts (GII), providing a modulus of elasticity and juxtaposition able to support occlusal loads 5 . One disadvantage of this technique is that the indirect anatomic post is time-consuming and expensive to make, as it requires a laboratory step ${ }^{15}$. However, this is also required for manufacturing the cast metal post-and-core.

The findings of the present study indicate that the anatomic posts seem to be a good alternative for restoring flared root canals. However, care should be taken when extrapolating the results of laboratory studies to the clinical situation. Clinically, the forces generated by masticatory activities occur in several directions instead of a single direction, as observed in in vitro compressive fracture strength tests. Therefore, further in vitro and in vivo studies are needed to confirm the results of this investigation.

\section{CONCLUSIONS}

Within the limitations of this in vitro study, the following conclusions may be drawn: 1. The use of intraradicular posts increased the fracture strength of the flared roots; 2 . Direct 
and indirect anatomic posts could be an alternative to cast metal post-and-core during the treatment of flared roots; 3 . The fracture strength of teeth restored with cast metal postand-core and anatomic fiber posts, fabricated by both direct and indirect techniques, presented similar values; 4. As opposed to the cast metal post-and-core, all fractures presented by the anatomic fiber posts were favorable.

\section{REFERENCES}

1-Akkayan B, Gulmez T. Resistance to fracture of endodontically treated restored with different posts system. J Prosthet Dent. 2002;87:431-7.

2- Asmussen E, Peutzfeldt A, Heitmann T. Stiffness, elastic limit, and strength of newer types of endodontic posts. J Dent. 1999;27:275-8.

3- Bonfante G, Kaizer OB, Pegoraro LF, Valle AL. Fracture strength of teeth with flared root canals restored with glass fibre posts. Int Dent J. 2007;57:153-60

4- Bortoluzzi EA, Souza EM, Reis JMSN, Esberard RM, Tanomaru-Filho $M$. Fracture strength of bovine incisors after intra-radicular treatment with MTA in an experimental immature tooth model. Int Endod J. 2007;40:68491.

5- Boudrias P, Sakkal S, Petrova Y. Anatomical post design meets quartz fiber technology: rationale and case report. Compend Contin Educ Dent. 2001;22:337-40.

6- Braga RR, Boaro LC, Kuroe T, Azevedo CL, Singer JM. Influence of cavity dimensions and their derivatives (volume and ' $\mathrm{C}$ ' factor) on shrinkage stress development and microleakage of composite restorations. Dent Mater. 2006;22:818-23.

7- Dean JP, Jeansonne BG, Sarkar N. In vitro evaluation of a carbon fiber post. J Endod. 1998;24:807-10

8- Duret B, Reynaud M, Duret F. Un nouveau concept de reconstitution corono-radiculaire: le composipost. Chir Dent France. 1990;60:131-41.

9- Ferrari M, Cagidiaco MC, Goracci C, Vichi A, Mason PN, Radovic I, et al. Long-term retrospective study of the clinical performance of fiber posts. Am J Dent. 2007;20:287-91.

10- Ferrari M, Vichi A, Garcia-Godoy F. Clinical evaluation of fiber-resin forced epoxy-resin posts and cast post-and-core. Am J Dent. 2000;13:15B$8 \mathrm{~B}$.

11- Fraga RC, Chaves BT, Mello GS, Siqueira JF Jr. Fracture resistance of endodontically treated roots after restoration. J Oral Rehabil. 1998;25:809-13.

12- Fredriksson M, Astback J, Pamenius M, Arvidson K. A retrospective study of 236 patients with teeth restored by carbon fiber-reinforced epoxy resin posts. J Prosthet Dent. 1998;80:151-7.

13- Freedman G. The carbon fiber post: metal-free, post-endodontic rehabilitation. Oral Health. 1996;86:23-30.

14- Grandini S, Goracci C, Monticelli F, Borracchini A, Ferrari M. SEM evaluation of the cement layer thickness after luting two different posts. J Adhes Dent. 2005; 7:235-40.

15- Grandini S, Sapio S, Simonetti M. Use of anatomic post and core for reconstructing an endodontically treated tooth: a case report. J Adhes Dent 2003;5:243-7.
16- Heidecke G, Butz F, Strub JR. Fracture strength and survival rate of endodontically treated maxillary incisors with approximal cavities after restoration with different posts and core systems: an in-vitro study. J Dent. 2001;29:427-33.

17- Isidor F, Ödman P, Brondum K. Intermittent loading of teeth restored using prefabricated carbon fiber posts. Int J Prosthodont. 1996;9:131-6.

18- Lambjerg-Hansen H, Asmussen E. Mechanical properties of endodontic posts. J Oral Rehabil. 1997;24:882-7.

19- Lassila LP, Tanner J, Le Bell AM, Narva K, Vallittu PK. Flexural properties of fiber reinforced root canal posts. Dent Mater. 2004;20:2936.

20- Lui JL. Cermet reinforcement of a weakened endodontically treated root: a case report. Quintessence Int. 1992;23:533-8.

21- Melo MP, Valle AL, Pereira JR, Bonachela WC, Pegoraro LF, Bonfante G. Evaluation of fracture resistance of endodontically treated teeth restored with prefabricated posts and composites with varying quantities of remaining coronal tooth structure. J Appl Oral Sci. 2005;13:141-6.

22- Mendonza DB, Eakle WS, Kahl EA, Ho R. Root reinforcement with a resin bonded performed post. J Prosthet Dent. 1997;78:10-5.

23- Mitsui FH, Marchi GM, Pimenta LA, Ferraresi PM. In vitro study of fracture resistance of bovine roots using different intraradicular post systems. Quintessence Int. 2004;35:612-6.

24- Morgano SM. Restoration of pulpless teeth: application of traditional principles in present and future contexts. J Prosthet Dent. 1996;75:41922.

25- Saupe WA, Gluskin AH, Radeke RA. A comparative study of fracture resistance between morphologic dowel and cores a resin-reinforced dowel system in the intra-radicular restoration of structurally compromised roots. Quintessence Int. 1996;27:483-91.

26- Sirimai S, Riis DN, Morgano SM. An in vitro study of the fracture resistance and the incidence of vertical root fracture of pulpless teeth restored with six post-and-core systems. J Prosthet Dent. 1999;81:262-9.

27- Soares CJ Pizi ECG, Fonseca RB, Martins LRM. Influence of root embedment material and periodontal ligament simulation on fracture resistance tests. Braz Oral Res. 2005;19:11-6.

28- Sorensen JA, Engleman MJ. Ferrule design and Fracture resistance of endodontically treated teeth. J Prosthet Dent. 1990;63:529-35.

29- Terry DA. Restoring the intraradicular space with direct composite resins: fiber-reinforced post-and-core system. Pract Proced Aesthet Dent. $2004 ; 16: 445-7$

30- Yoldas O, Akova T, Uysal H. An experimental analysis of stresses in simulated flared root canals subjected to various post-core applications. $\mathrm{J}$ Oral Rehabil. 2005;32:427-32. 